\title{
HF Analysis of Thin Horizontal Central-Fed Conductor above Lossy Homogeneous Soil
}

\author{
Farid Monsefi $^{1}$, Milica Rančić ${ }^{1,2}$, Slavoljub Aleksić ${ }^{2}$, Sergei Silvestrov ${ }^{1}$ \\ ${ }^{1}$ Division of Applied Mathematics, Mälardalen University, UKK, Västerås, Sweden, \\ \{farid.monsefi, milica.rancic, sergei.silvestrov\}@mdh.se \\ ${ }^{2}$ Department of Theoretical Electrical Engineering, University of Niš, ELFAK, Niš, Serbia, \\ \{milica.rancic, slavoljub.aleksic\}@elfak.ni.ac.rs
}

\begin{abstract}
In this paper, the authors perform HF analysis of a thin horizontal conductor fed in its center, and arbitrarily positioned above lossy homogeneous ground of known electrical parameters. The approach is based on the electric-field integral equation method, and formulation of the Hallén's integral equation. This equation is then solved for the current using the pointmatching method. The Sommerfeld's integrals that express the influence of the lossy ground, and that appear in these calculations, are solved approximately. Thorough analysis is performed in order to observe the influence of different parameters of the geometry and the ground on current distribution in the specified frequency range. Furthermore, the verification of the method is done by comparison with the exact model based on the full-wave theory.
\end{abstract}

Index Terms-horizontal wire conductor; lossy homogeneous soil; point-matching method; polynomial current approximation; Sommerfeld's integral

\section{INTRODUCTION}

The estimation of the influence of the lossy homogeneous soil (LHS) on the near-field characteristics of radiating elements positioned in its close proximity has been intensively studied [116]. A number of approaches have been applied in that sense, ranging from the exact full-wave based ones [4, 5, 13-16] to different forms of approximate, less time-consuming ones, [1-3, $6,8-16]$. Although the approximate methods introduce a certain level of calculation error, their simplicity is of interest in the EMC studies. For that reason, finding an approximate, but satisfyingly accurate method, applicable to wide range of parameters of the ground and geometry, and in the desired frequency range, is often a goal of researches conducted in this field.

In this paper, authors apply one such method that is based on the numerical solution of one formulation of the electric field integral equation, the Hallén's integral equation, using the point-matching method, [7]. This way obtained system of linear equations involves improper Sommerfeld's integrals that are here modelled by the so-called TIA and OIA models (two- and one- image approximations) proposed in [8-12]. As a result, the current distribution is obtained in a wide frequency range $(10 \mathrm{kHz}-10 \mathrm{MHz})$ for different ground conductivities, and positions of the thin wire conductor. The results are compared to corresponding ones from [13] where the authors based their exact model on the full-wave theory, solving the mixed potential integral equation by the method of moments, [13-16].

This paper is in part supported by the EUROWEB Project funded by the Erasmus Mundus Action II programme of the European Commission (http://www.mrtc.mdh.se/euroweb), and the RALF3 project funded by the Swedish Foundation for Strategic Research (SSF).

The second author would like to thank members of the Division of Applied Mathematics at the MDH University in Västerås, Sweden for inspiring and fruitful collaboration.

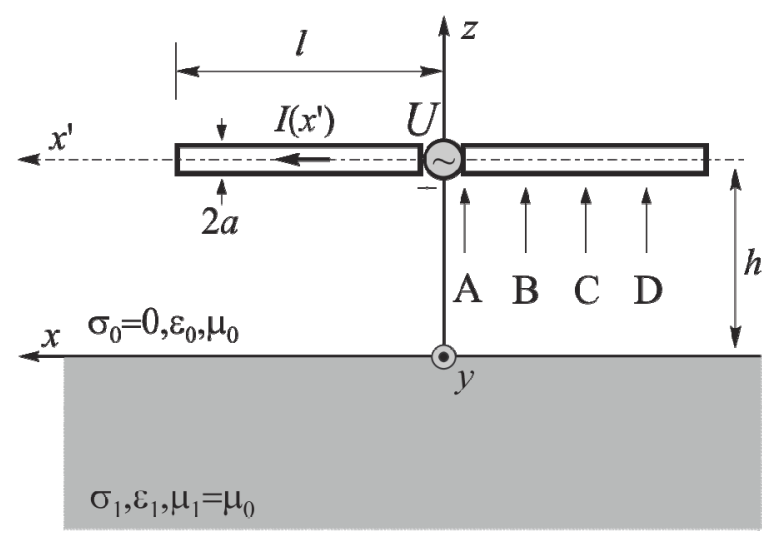

Figure 1. Illustration of the horizontal central-fed conductor above LHS.

\section{MATHEMATICAL MODELLING}

Let us observe a thin wire horizontal conductor fed in the middle $\left(l_{1}=l_{2}=l\right)$ with two halves having equal cross-section radius $\left(a_{1}=a_{2}=a\right)$, as shown in Fig. 1 . The conductor is positioned in the air at arbitrary height $h$ above LHS of known electrical parameters. In order to calculate the current distribution along the observed conductor, the integral equation of Hallén's type is formed satisfying the condition for the tangential component of the electric field on the conductor's surface, [9-12]:

$$
\begin{aligned}
& 4 \pi \underline{\sigma}_{0} \Pi_{x 00}^{*}=C_{1} \cos \left(\beta_{0} x\right)-\frac{\mathrm{j} U}{60} \sin \left(\beta_{0} x\right)+ \\
& +\underline{\mathrm{j}}_{0} \int_{-l}^{l} I\left(x^{\prime}\right) \int_{s=0}^{x}\left[\begin{array}{l}
\left(1-\underline{n}^{-2}\right) K_{0}\left(r_{2 k}\right)- \\
-\underline{n}^{-2} S_{00}^{v}\left(r_{2 k}\right)+S_{00}^{h}\left(r_{2 k}\right)
\end{array}\right]_{\substack{x=s \\
y=a \\
z=h}} \\
& \cdot \sin \left(\beta_{0}(x-s)\right) \mathrm{d} s \mathrm{~d} x^{\prime}
\end{aligned}
$$

where $C_{1}$ - constant and

$$
\Pi_{x 00}^{*}=\frac{1}{4 \pi \underline{\sigma}_{0}} \int_{-l}^{l} I\left(x^{\prime}\right)\left[\begin{array}{l}
K_{0}\left(r_{1 k}\right)+ \\
+\left(\underline{n}^{-2}-1\right) K_{0}\left(r_{2 k}\right)+ \\
+\underline{n}^{-2} S_{00}^{v}\left(r_{2 k}\right)
\end{array}\right] \mathrm{d} x^{\prime},
$$




$$
\begin{aligned}
& S_{00}^{v}\left(r_{2 k}\right)=\int_{\alpha=0}^{\infty} \widetilde{R}_{z 10}(\alpha) \widetilde{K}_{0}\left(\alpha, r_{2 k}\right) \mathrm{d} \alpha, \\
& S_{00}^{h}\left(r_{2 k}\right)=\int_{\alpha=0}^{\infty} \widetilde{R}_{\eta 10}(\alpha) \widetilde{K}_{0}\left(\alpha, r_{2 k}\right) \mathrm{d} \alpha,
\end{aligned}
$$

and $K_{0}\left(r_{2 k}\right)=e^{-\underline{\gamma}_{0} r_{2 k}} / r_{2 k}=\int_{\alpha=0}^{\infty} \widetilde{K}_{00}\left(\alpha, r_{2 k}\right) \mathrm{d} \alpha$ in (1) and (2) presents the standard potential kernel, while the first terms in both integrands of (3a-b) represent spectral reflection coefficients:

$$
\begin{gathered}
\widetilde{R}_{z 10}(\alpha)=\frac{\underline{n}^{2} u_{0}-u_{1}}{\underline{n}^{2} u_{0}+u_{1}}, u_{i}=\sqrt{\alpha^{2}+\underline{\gamma}_{i}^{2}}, i=0,1, \\
\widetilde{R}_{\eta 10}(\alpha)=\frac{u_{0}-u_{1}}{u_{0}+u_{1}}, u_{i}=\sqrt{\alpha^{2}+\underline{\gamma}_{i}^{2}}, i=0,1,
\end{gathered}
$$

$\underline{\gamma}_{i}$ - propagation constant and $\underline{\sigma}_{i^{-}}$equivalent complex conductivity of the $i$-th medium; $\underline{n}=\underline{\gamma}_{1} / \underline{\gamma}_{0}=\sqrt{\underline{\varepsilon}_{r 1}}$ - complex refractive index (in the air: $\chi_{0}=\mathrm{j} \beta_{0}$ ); $\underline{\varepsilon}_{r 1} \approx \varepsilon_{r 1}-\mathrm{j} 60 \sigma_{1} \lambda_{0}-$ complex relative permittivity; $r_{i k}=\sqrt{\left(x-x^{\prime}\right)^{2}+y^{2}+\left(z+(-1)^{i} h\right)^{2}}$, $i=1,2$; and $\alpha$ - variable over which the integration is done. Two simple approximate solutions of Sommerfeld's integrals (3a-b) have been previously proposed by the second author and are applied in this paper. Let us assume (4a) in the TIA (twoimage approximation) form, [8], [12]:

$$
\widetilde{R}_{z 10}\left(u_{0}\right) \cong B_{v}+A_{1 v} e^{-\left(u_{0}-\underline{\gamma}_{0}\right) \underline{d}_{v}},
$$

where $B_{v}, A_{1 v}$ and $\underline{d}_{v}$ are unknown complex constants. Matching (4a) and (5) at $u_{0} \rightarrow \infty$ and $u_{0}=\underline{\gamma}_{0}$, and the first derivative of the same expressions at $u_{0}=\underline{\gamma}_{0}$, the following values for the unknown complex constants in (5) are obtained: $B_{v}=R_{\infty}, A_{1 v}=R_{0}-R_{\infty}, \underline{d}_{v}=\left(1+\underline{n}^{-2}\right) / \underline{\gamma}_{0}, \quad R_{\infty}=$ $=\widetilde{R}_{z 10}\left(u_{0} \rightarrow \infty\right)=\left(\underline{n}^{2}-1\right) /\left(\underline{n}^{2}+1\right)$ and $R_{0}=(\underline{n}-1) /(\underline{n}+1)$. Now, (3a) becomes

$$
S_{00}^{v}\left(r_{2 k}\right) \cong R_{\infty} K_{0}\left(r_{2 k}\right)+\left(R_{0}-R_{\infty}\right) e^{\underline{\gamma} 0 \underline{d} v} K_{0}\left(r_{2 k v}\right),
$$

where $r_{2 k v}=\sqrt{\rho_{k}^{\prime 2}+\left(z+z_{k}^{\prime}+\underline{d}_{v}\right)^{2}}$. Now, assume (4b) as:

$$
\widetilde{R}_{\eta 10}\left(u_{0}\right) \cong B_{h}+A_{1 h} \mathrm{e}^{-\left(u_{0}-\underline{\gamma}_{0}\right) \underline{d} h},
$$

where $B_{h}, A_{1 h}$ and $\underline{d}_{h}$ - unknown complex constants. After matching (4b) and (7) at points $u_{0} \rightarrow \infty$ and $u_{0}=\underline{\gamma}_{0}$, and their first derivatives at $u_{0}=\underline{\gamma}_{0}$, we get values $B_{h}=0$,
$A_{1 h}=-R_{0}$, and $\underline{d}_{h}=2 /\left(\underline{\gamma}_{0} \underline{n}\right)$, i.e. (3b) gets the OIA (oneimage approximation) form, [10-12]:

$S_{00}^{h}\left(r_{2 k}\right) \cong-R_{0} e^{\underline{\gamma_{0}}{ }^{\underline{d}} h} K_{0}\left(r_{2 k h}\right), r_{2 k h}=\sqrt{\rho_{k}^{\prime 2}+\left(z+h+\underline{d}_{h}\right)^{2}}$.

The integral equation (1) is solved applying the pointmatching method [7] while adopting the entire domain polynomial current approximation for the current, [3]:

$$
I\left(u^{\prime}=x^{\prime} / l\right)=\sum_{m=0}^{\mathrm{M}} I_{m} u^{\prime m}, 0 \leq u^{\prime} \leq 1,
$$

where $I_{\mathrm{m}}, \mathrm{m}=0,1, \ldots \mathrm{M}$, are complex current coefficients.

\section{NUMERICAL RESULTS}

Firstly, results for the current distribution's magnitude and phase are given in Fig. 2 and Table I. The conductor is $2 l=20 \mathrm{~m}$ long with the cross-section radius of $a=0.007 \mathrm{~m}$, and it is placed at $h=1.0 \mathrm{~m}$ above lossy ground with electrical permittivity $\varepsilon_{r 1}=10$. In this case, the variable parameter is the frequency that takes values from a wide range of importance for EMC studies $(10 \mathrm{kHz}$ to $10 \mathrm{MHz})$. In Fig. 2, the current magnitude and phase along a half of the conductor are shown against the values from [13] for the case of the specific conductivity of $\sigma_{1}=0.001 \mathrm{~S} / \mathrm{m}$. The results of more extensive analysis can be observed from Table I that lists values of the current magnitude and phase at four different points along a half of the conductor, and for three different values of the specific conductivity of the ground, $\sigma_{1}=0.001,0.01,0.1 \mathrm{~S} / \mathrm{m}$.

Further, the influence of the conductor's position on the current distribution has been analyzed. The results are graphically illustrated in Figs. 3-5 together with the ones from [13]. Three cases were observed that correspond to heights $h=0.1$, $1.0,5.0 \mathrm{~m}$. The current has been calculated at frequency of 10 $\mathrm{MHz}$, and each figure set corresponds to a different value of the specific conductivity $\left(\sigma_{1}=0.001,0.01,0.1 \mathrm{~S} / \mathrm{m}\right)$. Dimensions of the conductor are the same as previously.

Next example deals with the dependence of the current magnitude and phase, calculated at the conductor's feeding point (A in Fig. 1), on the frequency in the range from $10 \mathrm{kHz}$ to $10 \mathrm{MHz}$, Figs. 6-8. Each figure set corresponds to a different value of the specific conductivity $\left(\sigma_{1}=0.001,0.01,0.1\right.$ $\mathrm{S} / \mathrm{m})$. The influence of the conductor's position in the observed frequency range has also been incorporated through a variable parameter $h$ denoting the height above the ground, and taking values: $h=0.1,1.0,5.0 \mathrm{~m}$.

Finally, current distribution's magnitude and phase at frequency of $10 \mathrm{MHz}$, can be observed from Fig. 9. The conductor has the same dimensions as previously, and it is placed at $h=1.0 \mathrm{~m}$ above lossy ground with electrical permittivity $\varepsilon_{r 1}=10$. The value of the specific conductivity has been taken as a parameter that takes values: $\sigma_{1}=0.001,0.01$, $0.1 \mathrm{~S} / \mathrm{m}$. Comparison has been done with the corresponding results from [13]. 

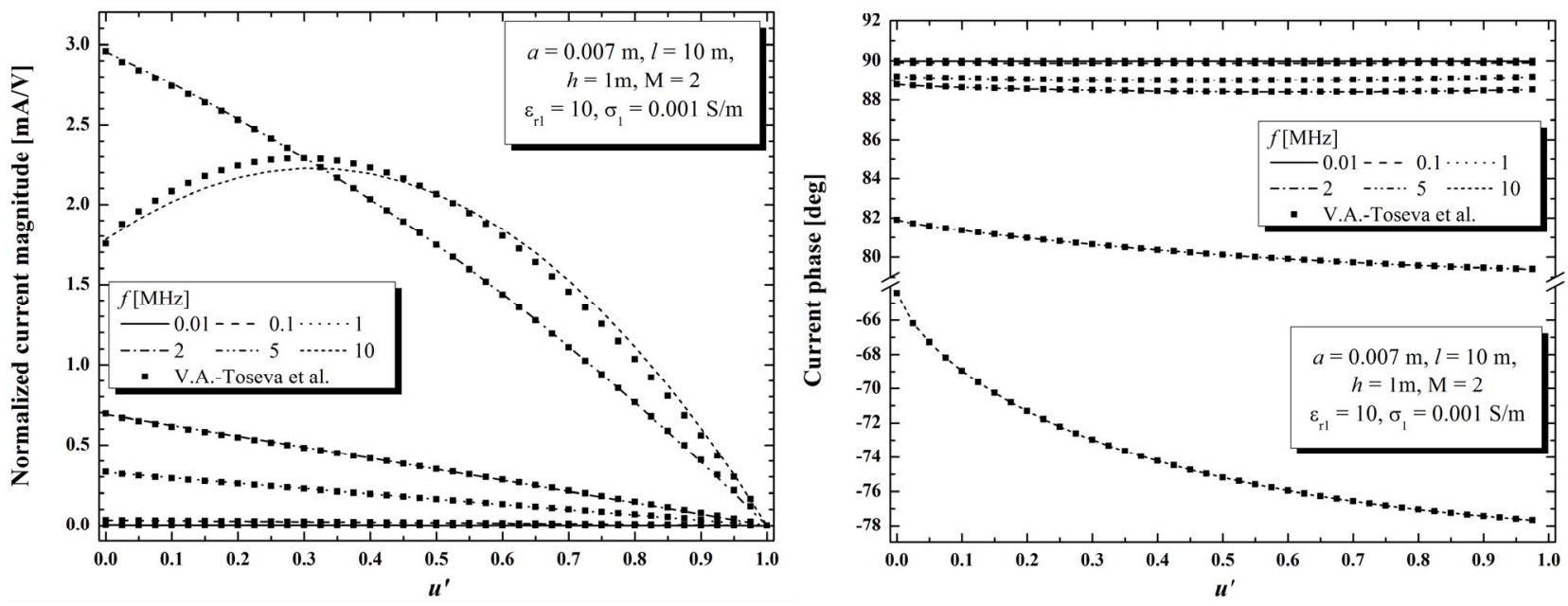

Figure 2. Current magnitude and phase along a half of the conductor above LHS for different frequences. Ground conductivity is $\sigma_{1}=0.001 \mathrm{~S} / \mathrm{m}$.

TABle I. Magnitude and Phase of the Normalized Current Distribution at DifFerent Points along the Conductor Versus Frequency: $l=10 \mathrm{~m}, a=0.007 \mathrm{~m}, h=1.0 \mathrm{~m}, \varepsilon_{r 1}=10$.

\begin{tabular}{|c|c|c|c|c|c|c|c|c|c|c|c|c|c|}
\hline \multicolumn{7}{|c|}{ This method } & \multicolumn{7}{|c|}{ V.A.-Toseva et al. } \\
\hline $\begin{array}{c}\text { B } \\
l=2.5 \mathrm{~m}\end{array}$ & \multicolumn{2}{|c|}{$\sigma_{1}=0.001 \mathrm{~S} / \mathrm{m}$} & \multicolumn{2}{|c|}{$\sigma_{1}=0.01 \mathrm{~S} / \mathrm{m}$} & \multicolumn{2}{|c|}{$\sigma_{1}=0.1 \mathrm{~S} / \mathrm{m}$} & $\begin{array}{c}\text { B } \\
l=2.5 \mathrm{~m}\end{array}$ & \multicolumn{2}{|c|}{$\sigma_{1}=0.001 \mathrm{~S} / \mathrm{m}$} & \multicolumn{2}{|c|}{$\sigma_{1}=0.01 \mathrm{~S} / \mathrm{m}$} & \multicolumn{2}{|c|}{$\sigma_{1}=0.1 \mathrm{~S} / \mathrm{m}$} \\
\hline$f[\mathbf{M H z}]$ & $\operatorname{Abs}\{\mathbf{I n}\}$ & $\operatorname{Arg}\{\mathbf{I n}\}$ & $\operatorname{Abs}\{\mathbf{I n}\}$ & $\operatorname{Arg}\{\operatorname{In}\}$ & $\operatorname{Abs}\{\mathbf{I n}\}$ & $\operatorname{Arg}\{\operatorname{In}\}$ & $f[\mathrm{MHz}]$ & $\operatorname{Abs}\{\mathbf{I n}\}$ & $\operatorname{Arg}\{\mathbf{I n}\}$ & $\operatorname{Abs}\{\mathbf{I n}\}$ & $\operatorname{Arg}\{\mathbf{I n}\}$ & $\operatorname{Abs}\{\mathbf{I n}\}$ & $\operatorname{Arg}\{\mathbf{I n}\}$ \\
\hline 0.01 & 0.002 & 89.989 & 0.002 & 89.999 & 0.002 & 90.000 & 0.01 & 0.002 & 89.988 & 0.002 & 89.999 & 0.002 & 90.000 \\
\hline 0.1 & 0.024 & 89.885 & 0.024 & 89.988 & 0.024 & 89.998 & 0.1 & 0.024 & 89.879 & 0.024 & 89.987 & 0.024 & 89.998 \\
\hline 1 & 0.245 & 89.083 & 0.247 & 89.804 & 0.247 & 89.922 & 1 & 0.242 & 89.036 & 0.244 & 89.801 & 0.243 & 89.922 \\
\hline 2 & 0.521 & 88.551 & 0.528 & 89.376 & 0.524 & 89.729 & 2 & 0.514 & 88.518 & 0.522 & 89.376 & 0.518 & 89.729 \\
\hline 5 & 2.418 & 80.215 & 2.457 & 83.638 & 2.312 & 87.545 & 5 & 2.416 & 80.801 & 2.458 & 83.764 & 2.315 & 87.548 \\
\hline 10 & 2.209 & -71.560 & 2.210 & -76.918 & 2.433 & -84.109 & 10 & 2.281 & -72.213 & 2.288 & -77.227 & 2.517 & -84.133 \\
\hline $\begin{array}{c}\mathrm{C} \\
l=5.0 \mathrm{~m}\end{array}$ & \multicolumn{2}{|c|}{$\sigma_{1}=0.001 \mathrm{~S} / \mathrm{m}$} & \multicolumn{2}{|c|}{$\sigma_{1}=0.01 \mathrm{~S} / \mathrm{m}$} & \multicolumn{2}{|c|}{$\sigma_{1}=0.1 \mathrm{~S} / \mathrm{m}$} & $\begin{array}{c}\mathrm{C} \\
l=5.0 \mathrm{~m}\end{array}$ & \multicolumn{2}{|c|}{$\sigma_{1}=0.001 \mathrm{~S} / \mathrm{m}$} & \multicolumn{2}{|c|}{$\sigma_{1}=0.01 \mathrm{~S} / \mathrm{m}$} & \multicolumn{2}{|c|}{$\sigma_{1}=0.1 \mathrm{~S} / \mathrm{m}$} \\
\hline$f[\mathrm{MHz}]$ & $\operatorname{Abs}\{\mathbf{I n}\}$ & $\operatorname{Arg}\{\mathbf{I n}\}$ & $\operatorname{Abs}\{\mathbf{I n}\}$ & $\operatorname{Arg}\{\mathbf{I n}\}$ & $\operatorname{Abs}\{\mathbf{I n}\}$ & $\operatorname{Arg}\{\mathbf{I n}\}$ & $f[\mathrm{MHz}]$ & $\operatorname{Abs}\{\mathbf{I n}\}$ & $\operatorname{Arg}\{\mathbf{I n}\}$ & $\operatorname{Abs}\{\mathbf{I n}\}$ & $\operatorname{Arg}\{\operatorname{In}\}$ & $\operatorname{Abs}\{\mathbf{I n}\}$ & $\operatorname{Arg}\{\mathbf{I n}\}$ \\
\hline 0.01 & 0.002 & 89.987 & 0.002 & 89.999 & 0.002 & 90.000 & 0.01 & 0.002 & 89.988 & 0.002 & 89.999 & 0.002 & 90.000 \\
\hline 0.1 & 0.016 & 89.874 & 0.016 & 89.987 & 0.016 & 89.998 & 0.1 & 0.016 & 89.876 & 0.016 & 89.987 & 0.016 & 89.998 \\
\hline 1 & 0.163 & 88.989 & 0.164 & 89.778 & 0.164 & 89.909 & 1 & 0.163 & 89.000 & 0.164 & 89.785 & 0.164 & 89.912 \\
\hline 2 & 0.349 & 88.375 & 0.354 & 89.287 & 0.351 & 89.686 & 2 & 0.350 & 88.415 & 0.355 & 89.313 & 0.352 & 89.695 \\
\hline 5 & 1.747 & 79.358 & 1.773 & 83.105 & 1.659 & 87.321 & 5 & 1.745 & 80.112 & 1.773 & 83.340 & 1.662 & 87.363 \\
\hline 10 & 2.066 & -74.838 & 2.076 & -79.303 & 2.257 & -85.098 & 10 & 2.065 & -75.191 & 2.080 & -79.434 & 2.261 & -85.070 \\
\hline $\begin{array}{c}\mathrm{D} \\
l=7.5 \mathrm{~m}\end{array}$ & \multicolumn{2}{|c|}{$\sigma_{1}=0.001 \mathrm{~S} / \mathrm{m}$} & \multicolumn{2}{|c|}{$\sigma_{1}=0.01 \mathrm{~S} / \mathrm{m}$} & \multicolumn{2}{|c|}{$\sigma_{1}=0.1 \mathrm{~S} / \mathrm{m}$} & $\begin{array}{c}\mathrm{D} \\
l=7.5 \mathrm{~m}\end{array}$ & \multicolumn{2}{|c|}{$\sigma_{1}=0.001 \mathrm{~S} / \mathrm{m}$} & \multicolumn{2}{|c|}{$\sigma_{1}=0.01 \mathrm{~S} / \mathrm{m}$} & \multicolumn{2}{|c|}{$\sigma_{1}=0.1 \mathrm{~S} / \mathrm{m}$} \\
\hline$f[\mathrm{MHz}]$ & $\operatorname{Abs}\{\mathbf{I n}\}$ & $\operatorname{Arg}\{\mathbf{I n}\}$ & $\operatorname{Abs}\{\operatorname{In}\}$ & $\operatorname{Arg}\{\operatorname{In}\}$ & $\operatorname{Abs}\{\mathbf{I n}\}$ & $\operatorname{Arg}\{\mathbf{I n}\}$ & $f[\mathbf{M H z}]$ & $\operatorname{Abs}\{\mathbf{I n}\}$ & $\operatorname{Arg}\{\mathbf{I n}\}$ & $\operatorname{Abs}\{\mathbf{I n}\}$ & $\operatorname{Arg}\{\operatorname{In}\}$ & $\operatorname{Abs}\{\operatorname{In}\}$ & $\operatorname{Arg}\{\mathbf{I n}\}$ \\
\hline 0.01 & 0.001 & 89.986 & 0.001 & 89.999 & 0.001 & 90.000 & 0.01 & 0.001 & 89.988 & 0.001 & 89.999 & 0.001 & 90.000 \\
\hline 0.1 & 0.008 & 89.863 & 0.008 & 89.986 & 0.008 & 89.998 & 0.1 & 0.008 & 89.884 & 0.008 & 89.988 & 0.008 & 89.998 \\
\hline 1 & 0.081 & 88.895 & 0.082 & 89.752 & 0.081 & 89.896 & 1 & 0.084 & 89.049 & 0.085 & 89.783 & 0.084 & 89.906 \\
\hline 2 & 0.175 & 88.200 & 0.178 & 89.200 & 0.176 & 89.643 & 2 & 0.181 & 88.413 & 0.184 & 89.286 & 0.182 & 89.674 \\
\hline 5 & 0.941 & 78.624 & 0.955 & 82.647 & 0.888 & 87.126 & 5 & 0.939 & 79.646 & 0.951 & 83.091 & 0.888 & 87.247 \\
\hline 10 & 1.331 & -76.650 & 1.340 & -80.613 & 1.446 & -85.653 & 10 & 1.253 & -76.812 & 1.262 & -80.574 & 1.363 & -85.578 \\
\hline
\end{tabular}



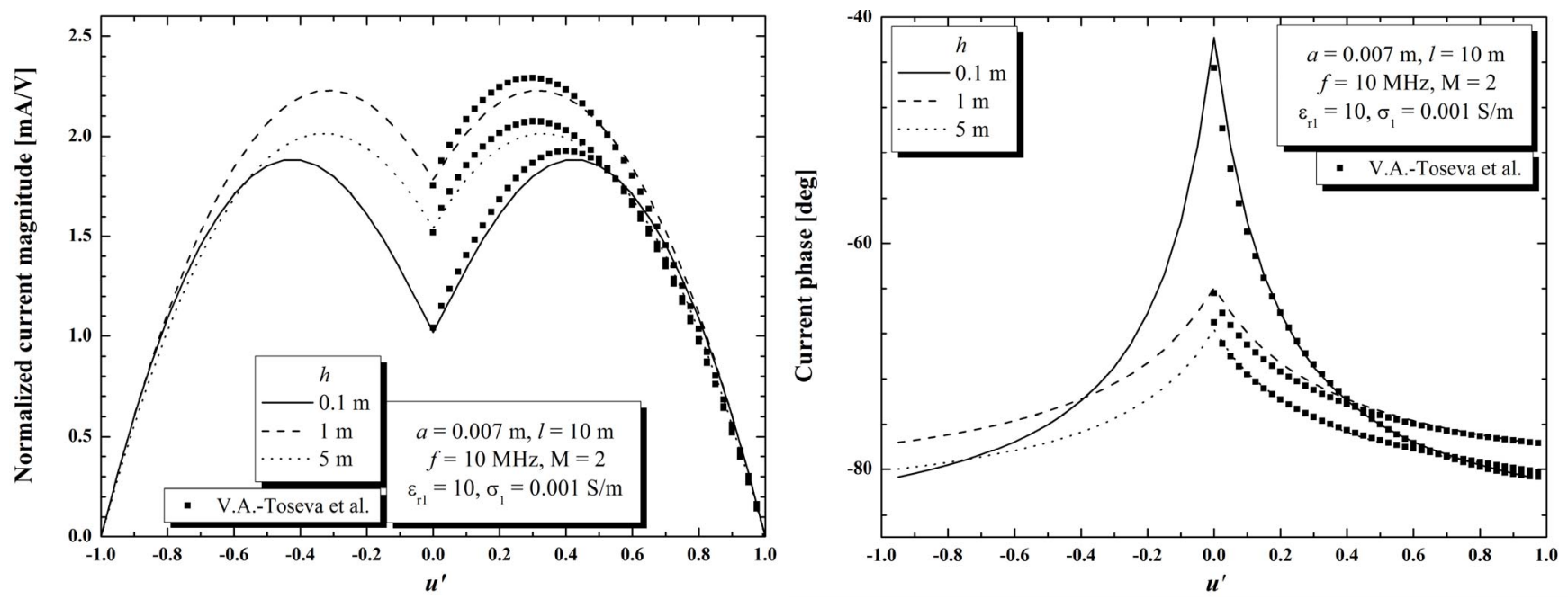

Figure 3. Current magnitude and phase along the conductor above LHS at different heights. Frequency is $10 \mathrm{MHz}$, and ground conductivity $\sigma_{1}=0.001 \mathrm{~S} / \mathrm{m}$.
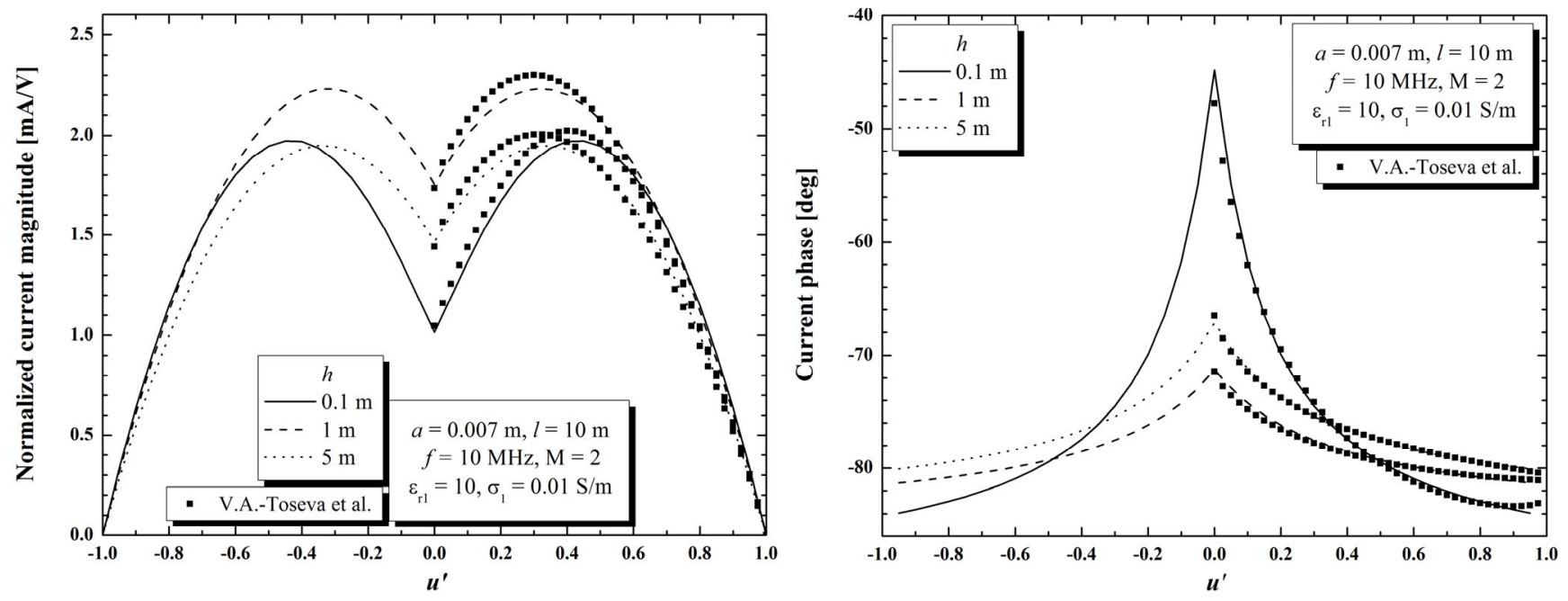

Figure 4. Current magnitude and phase along the conductor above LHS at different heights. Frequency is $10 \mathrm{MHz}$, and ground conductivity $\sigma_{1}=0.01 \mathrm{~S} / \mathrm{m}$.
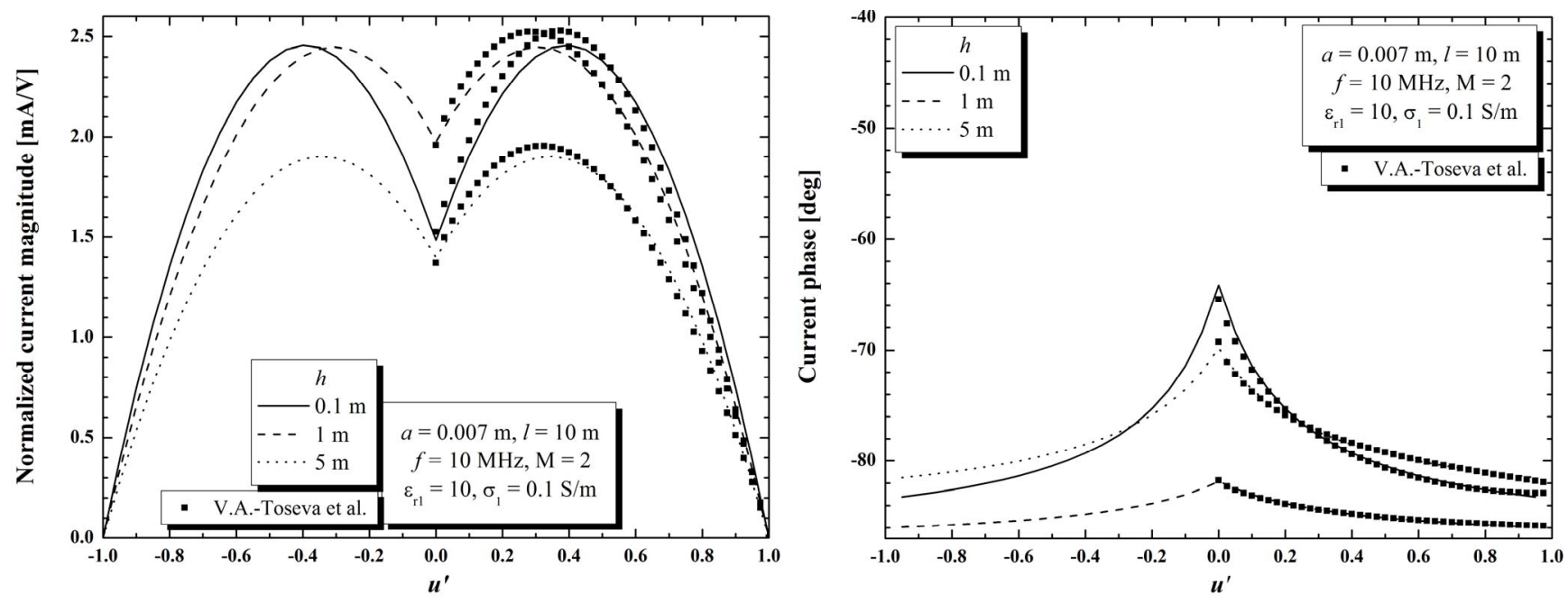

Figure 5. Current magnitude and phase along the conductor above LHS at different heights. Frequency is $10 \mathrm{MHz}$, and ground conductivity $\sigma_{1}=0.1 \mathrm{~S} / \mathrm{m}$. 

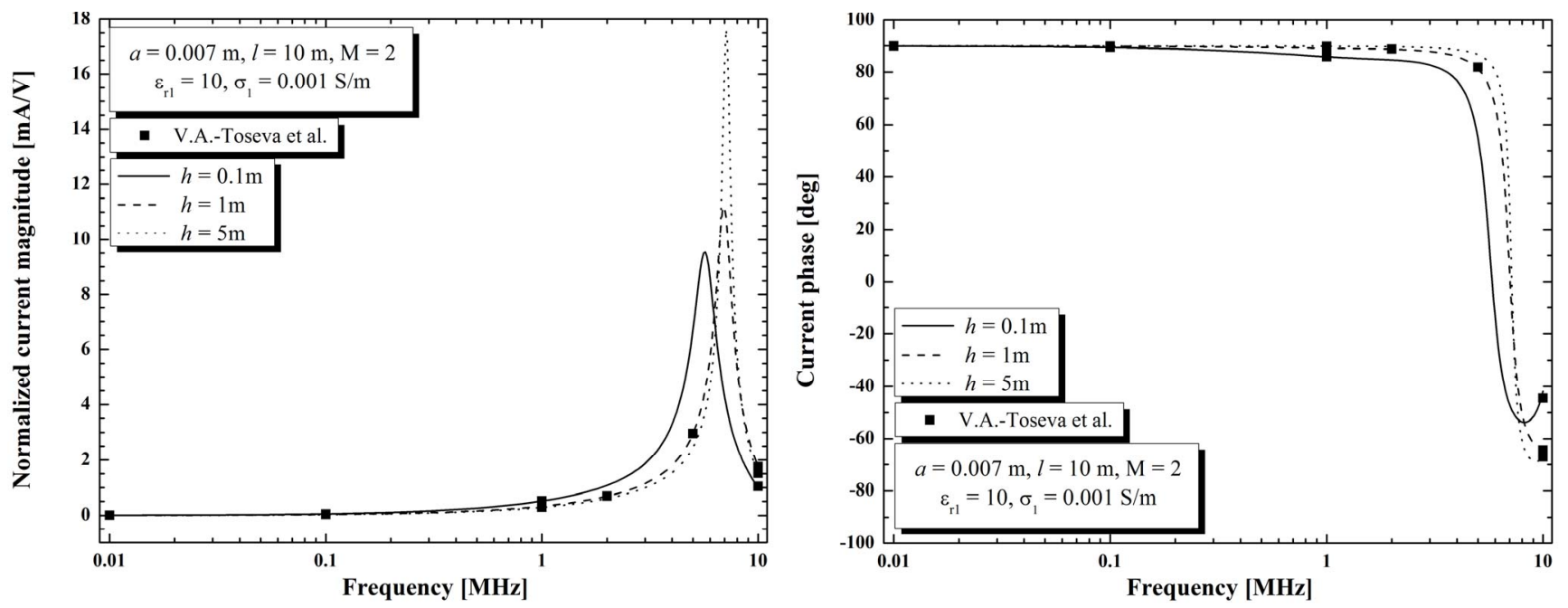

Figure 6. Current magnitude and phase at the conductor's feeding point versus frequency for different heights. Ground conductivity is $\sigma_{1}=0.001 \mathrm{~S} / \mathrm{m}$.
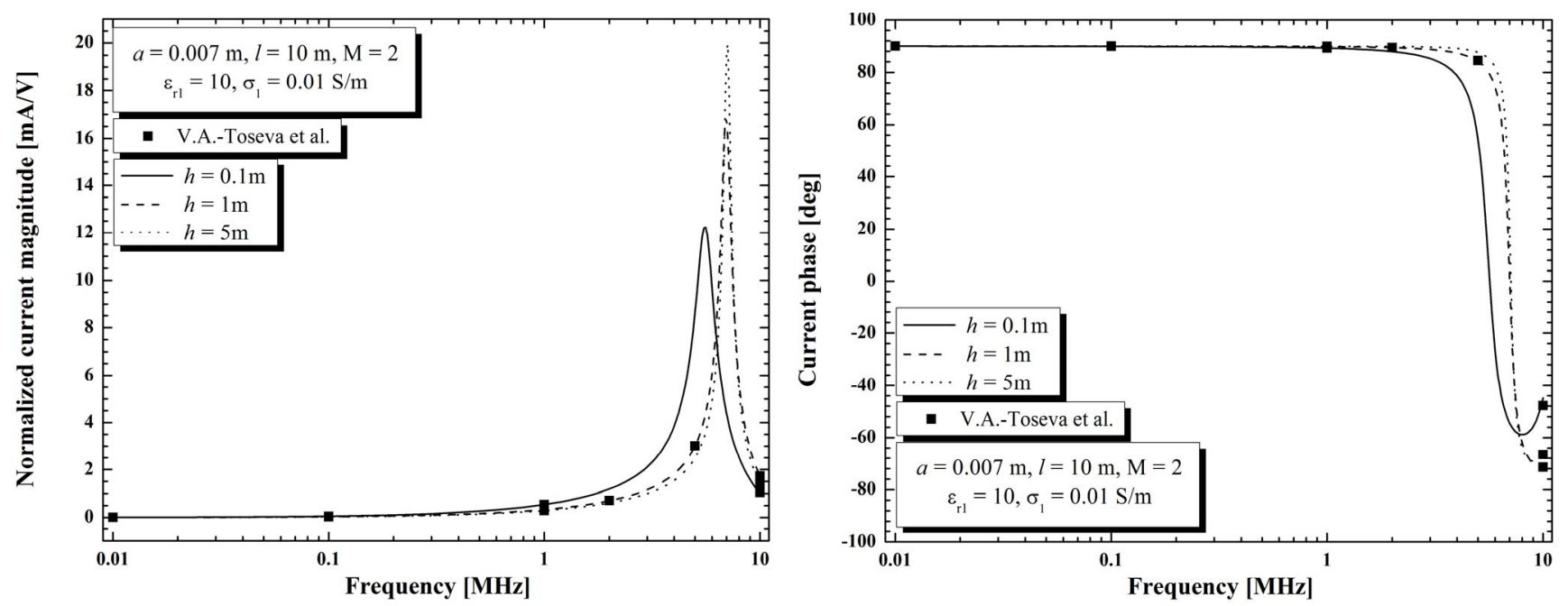

Figure 7. Current magnitude and phase at the conductor's feeding point versus frequency for different heights. Ground conductivity is $\sigma_{1}=0.01 \mathrm{~S} / \mathrm{m}$.
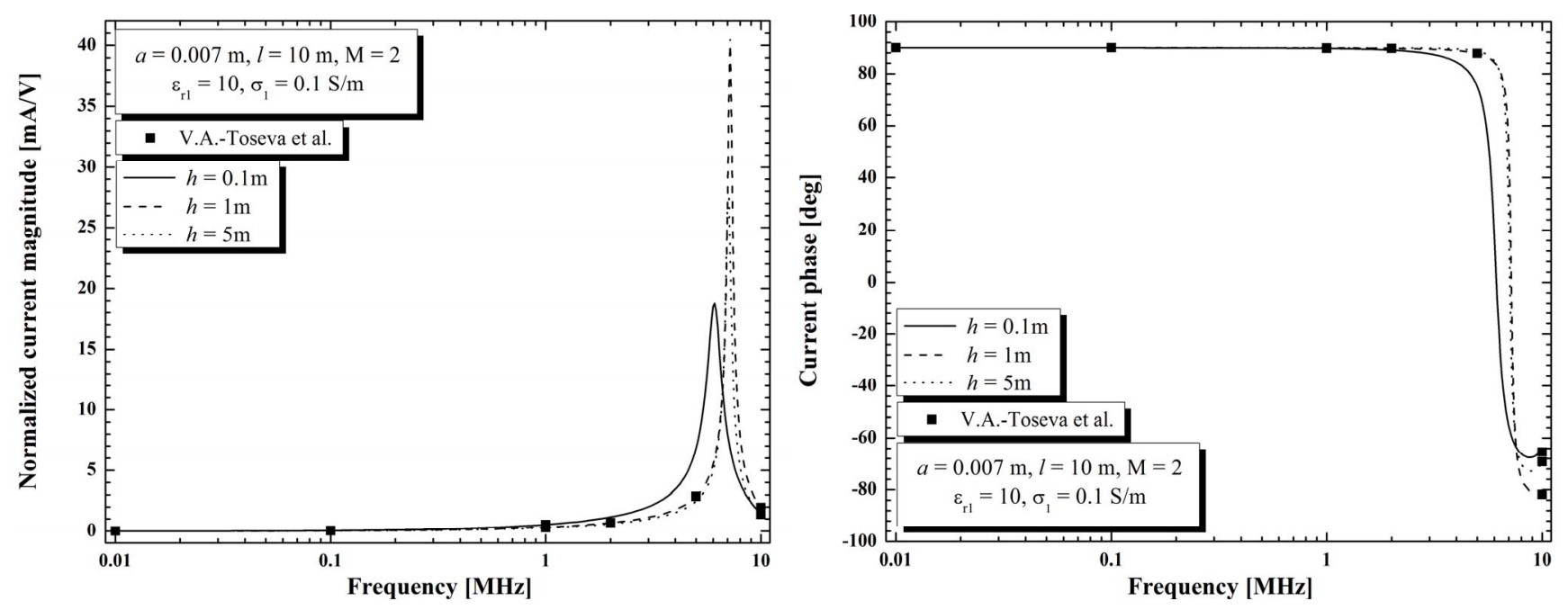

Figure 8. Current magnitude and phase at the conductor's feeding point versus frequency for different heights. Ground conductivity is $\sigma_{1}=0.1 \mathrm{~S} / \mathrm{m}$. 

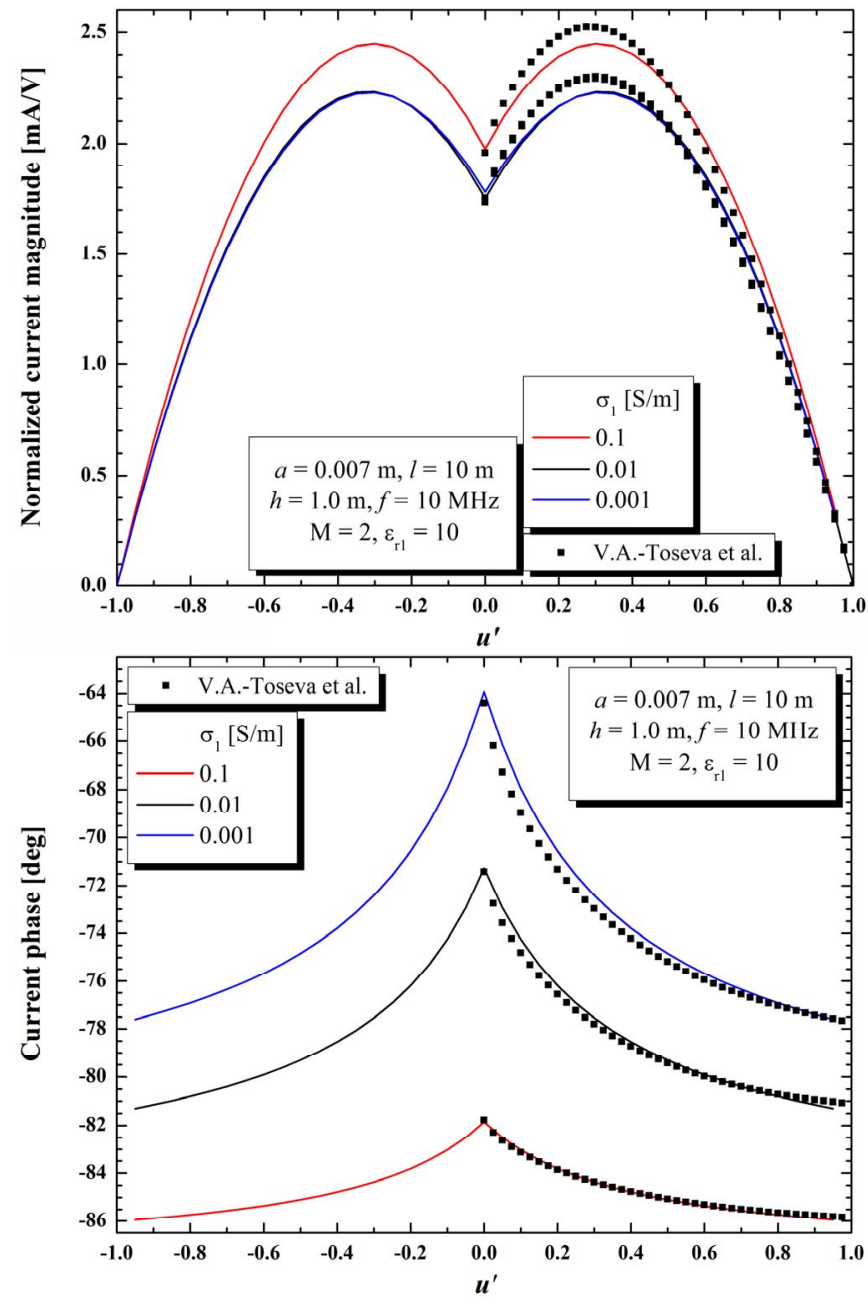

Figure 9. Current magnitude and phase along the conductorat height $h=1.0 \mathrm{~m}$ above LHS for different values of the ground conductivity. Frequency is $10 \mathrm{MHz}$.

\section{CONCLUSION}

Approximate method for the analysis of a horizontal centerfed thin wire conductor has been applied in this paper for the purpose of the current distribution evaluation in the case when the conductor is positioned in the air at arbitrary height above finitely conductive ground that can be treated as a homogenous medium. The goal of the paper was to inspect the validity of the applied method in the cases of interest for the EMC studies.

Therefore, the analysis has been performed in a wide frequency range, and for different positions of the conductor, as well as for various values of the soil's conductivity. It has been proven, based on the comparison with the exact model applied in [13-16], that the methodology used here yields very accurate results in the observed parameters' ranges. This indicates the possibilty of applying such method for analysis of different wire structures located in the air above LHS, and more importantly, even very close to the ground where the finite conductivity's influence is the greatest.

\section{REFERENCES}

[1] J. R. Wait and K. P. Spies, "On the image representation of the quasistatic fields of a line current source above the ground," Can.J. Phys., vol. 47, pp. 2731-2733, 1969.

[2] B. D. Popović, "Polynomial approximation of current along thin symmetrical cylindrical dipoles," Proc. Inst. Elec. Eng., vol. 117, no. 5, pp. 873-878, 1970.

[3] P. R. Bannister, "Extension of quasi-static range of finitely conducting earth image theory technique to other ranges," IEEE Trans. on AP, vol. 26, no. 3, pp. 507-508, 1978.

[4] J. V. Surutka and D. N. Mitić, "Horizontal dipole antenna above an imperfectly conducting ground fed by a two-wire line," Extrait du BULLETIN T. LXXVIII de l'Acedemie serb des sciences et des arts, Class des sciences techniques, vol. 19, pp. 1-14, 1981.

[5] B. D. Popović and D. Ž. Đurđević, "Entire-domain analysis of thin-wire antennas near or in lossy ground," IEE Proc., Microw. Antennas Propag., vol. 142, pp. 213-219, 1995.

[6] B. D. Popović and V. V. Petrović, "Horizontal wire antenna above lossy half-space: simple accurate image solution," International journal of numerical modelling: Electronic networks, devices and fields, vol. 9, pp. 194-199, 1996.

[7] C. A. Balanis, Antenna Theory: Analysis and Design, Chapter 8, 3rd ed., J. Wiley \& Sons, Inc., Hoboken, New Jersey, 2005, pp. 433-491.

[8] M. P. Rančić and P. D. Rančić, "Vertical dipole antenna above a lossy half-space: Efficient and accurate two-image approximation for the Sommerfeld's integral," in CD Proc. EuCAP'06, Nice, France, 2006, paper $\mathrm{N}^{\mathrm{o}} 121$.

[9] M. Rančić and P. Rančić, "Horizontal linear antennas above a lossy halfspace: A new model for the Sommerfeld's integral kernel,” Int. J. El. Commun. AEÜ, vol. 65, pp. 879-887, 2011.

[10] M. Rančić and S. Aleksić, "Horizontal dipole antenna very close to lossy half-space surface," Electrical Review, no. 7b, 2012, pp. 82-85 [ISEF 2011, Portugal, 2011, PS.4.19].

[11] M. P. Rancic, S. R. Aleksic, M. A. Khavanova, R. V. Petrov, A. S. Tatarenko, and M. I. Bichurin, "Analysis of symmetrical dipole antenna on the boundary between air and lossy half-space," Современные проблемы науки и образования, no. 6, pp.1-7, 2012.

[12] M. Rančić, "Analysis of Wire Antenna Structures in the Presence of Semi-Conducting Ground," Ph.D dissertation, Faculty of electronic engineering, University of Niš, Niš, Serbia, 2012.

[13] V. Arnautovski-Toseva, K. El Khamlichi Drissi, and K. Kerroum, "Comparison of approximate models of horizontal wire conductor above homogeneous ground," EuCAP 2012, Prague, Czech Republic, pp. 678682, 2012.

[14] V. Arnautovski-Toseva, K. El Khamlichi Drissi, C. Faure, C. Pasquier, and K. Kerroum, "TM plane wave coupling to wire conductors above homogeneous soil: Comparison between complex image and transmission line approach," 20th International Conference on Software, Telecommunications and Computer Networks (SoftCOM), 2012, Split, Croatia, pp. 1-5, 2012.

[15] V. Arnautovski-Toseva, K. El Khamlichi Drissi, K. Kerroum, S. Grceva, and L. Grcev, "Comparison of image and transmission line models of energized horizontal wire above two-layer soil," Automatika, vol. 53, pp. 38-48, 2012.

[16] V. Arnautovski-Toseva, K. El Khamlichi Drissi, and K. Kerroum, "Plane wave coupling to horizontal wire conductor above two-layer soil: Comparison of electromagnetic, complex image and transmission line models," International Symposium on Electromagnetic Compatibility (EMC EUROPE), 2012, Rome, Italy, pp. 1-6, 2012. 